\title{
A Rapid Method of Crude Oil Analysis Using FT-IR Spectroscopy
}

\author{
${ }^{*}$ I. Abdulkadir, ${ }^{1 S}$. Uba, ${ }^{2}$ A. Salihu A., ${ }^{3}$ M.N. Almustapha \\ 1Department of Chemistry Ahmadu Bello University, Zaria, Nigeria \\ 2Department of Biochemistry Ahmadu Bello University, Zaria, Nigeria \\ ${ }^{3}$ Department of Pure and Applied Chemistry, Usmanu Dan Fodiyo University, Sokoto, Nigeria. \\ [Corresponding Author: Ibrahim.abdulkadir@gmail.com: E : +2348132447776]
}

\begin{abstract}
This study determines the viability of the use of Fourier Transform Infrared (FTIR) spectroscopy as a substitute to traditional petroleum geochemical methods for crude oil characterisation. IR spectra of Crude oil sample containing a mixture of both degraded (sample 151) and non-degraded (sample 145) oils at different concentrations were determined. The IR fingerprints agree with results obtained from GC analysis. Partial least square regression analysis was used to predict saturates for omitted mixtures $(10$ and $80 \% 151)$ and also saturates of five other samples (i.e. $145,149,172, \mathrm{H} 1$ and AL10) within acceptable error limits. It therefore, follows, that although some improvements might still need to be made, FTIR spectroscopy can indeed be a viable, simple, cheaper and faster technique of crude oil characterisation compared with the traditional fractionation methods.
\end{abstract}

Keywords: FTIR-ATR spectroscopy; GC-MS; Partial least squares (PLSR). Rapid analysis.

\section{INTRODUCTION}

Since its recognition as a scientific discipline in 1959 (Hunt et al., 2002), petroleum geochemistry has developed into an established science that improves exploration and production efficiency (Peter and Fowler, 2002) and it is also used in solves other reservoir related problems (Larter and Aplin, 1995). The mainspring for this dynamism and diversification has been due to improvements/combination of already existing geochemical techniques (Larter and Aplin, 1995; Hunt, et al., 2002), or the discovery of entirely new techniques/applications in the petroleum industries (Larter and Aplin, 1995). This, itself, has been driven by the need in the techniques for increased sensitivity, specificity and sophistication on one hand (Hunt et al., 2002) and the need for simplicity and rapid response on the other (Larter and Aplin, 1995), since it is common to have up to 500 core extracts waiting to be screened (Larter and Aplin, 1995)

Prior to the advent of combined gas chromatography/mass spectroscopy (GCMS), sample characterization (Crude oil), had been carried out using liquid chromatography (LC), thin layer chromatography (TLC) and gas chromatography (GC) (Larter and Aplin, 1995). However, these techniques are lengthy, tediousand laborious, as well as expensive to run on a routine basis (Aske, 2001). It is therefore practically impossible to contemplate rapid analysis of an organic mixture having many components (i.e. more than 20) (Hunt et al., 2002).
Hence, "even the separation and identification of two or three major components could take a year or more using classical analytical methods" (Hunt et al., 2002). High pressure liquid chromatography has since been developed to reduce these difficulties (Aske, 2001).

Perhaps the most prolific of the geochemical analytical tool so far is gas chromatography (GC) (Speight, 1998). The technique has proved to be an exceptional and versatile instrumental tool for analysing low molecular weight compounds (volatiles)and has been a major factor in the successful identification of petroleum constituents (Speight, 1998). Its power lies behind its ability to combine with other analytical methods to produce distinct results. Some examples include gas chromatography-mass spectroscopy (GC-MS), gas chromatography-mass spectroscopy-mass spectroscopy (GC-MS-MS) (Peters and Fowler 2002), pyrolysis gas chromatography (PGC) (Speight, 1998; Hunt et al., 2002), gas chromatography-isotope ratio-mass spectroscopy (GC-IR-MS) (Larter and Aplin, 1995). Many key geochemical advances that facilitate successful oil-oil correlation and oil-source rock correlation include innovations in GC-MS, metastable-reaction monitoring-GC-MS and GC-MSMS (Peters and Fowler, 2001). Gas chromatography has been extensively used to fingerprint and evaluate reservoir compartmentalisation and connectivity (Larter and Aplin, 1995; Parmenyer et al., 2001), with the aid of star diagrams and other statistical methods 
of analysis using selected n-alkane ratios (Permanyer et al., 2002).

However, these techniques are still tedious (Parmenyer et al., 2002), time consumingand require extensive sample preparation and testing procedure, which could alter the sample properties irreversibly (Ryder et al., 2002). The need to develop a nonexpensive, simple and rapid on-site technique that can be used for general compositional analysis and in the field of reservoir geochemistry has led some workers to use vibrational spectroscopic instruments. These include, Fourier Transform Infrared (FTIR) and Synchronised Ultra-Violet Fluorescence (SUVF) (e.g. Parmenyer et al., 2002). Fourier Transform Infrared and Near Infrared (FT-NIR) spectroscopy in combination with chemometrics and statistical data analysis, provide a possibility for fast determination of different chemical parameters in crude oil (Aske et al., 2001; Hannisdal et al., 2005). These technique had been applied in the food industries (Yang et al., 2005), agriculture (Hosamani and Ganjihal, 2005), fuels and energy (Roehner and Hanson, 2001) and petroleum geochemistry (Sjoblom et al., 2003).

The aim of this work was to determine the viability of the use of Fourier transform infrared spectroscopyAttenuated total reflectance technique as a reliable substitute for crude oil analysis/characterisation compared to traditional GC-MS and also to determine the viability of its use as an on-site technique for determining oil mixing in reservoirs. This would be achieved by carrying out analysis of some degraded and non-degraded oil samples using the traditional method (i.e. LC, GC-MS) to characterise the oil samples and then conduct FTIR-ATR analysis on bulk oil samples collected from different locations.

\section{METHODOLOGY Sample preparation}

About $500 \mathrm{mg}$ of oil mixture was made containing approximately $10 \%$ of sample 151 and $90 \%$ of 145 in a vial. Other mixtures contained $20,50,80$ and $90 \%$ of sample 151 while the remaining percentages (i.e. $80,50,20$ and $10 \%$ respectively) were made up of sample $145.200 \mathrm{mg}$ of end-members (i.e. samples 151 and 145) were also measured into separate vials.

\section{Liquid and Gas chromatography}

About $20 \mathrm{mg}$ each of the five mixtures and two endmembers were taken and mixed with activated alumina $\left(\mathrm{Al}_{2} \mathrm{O}_{3}\right)$. Columns were gently packed with Silica $\left(\mathrm{SiO}_{2}\right)$ and activated alumina $\left(\mathrm{Al}_{2} \mathrm{O}_{3}\right)$ to a height of about $12 \mathrm{~cm}$ in a $4: 1$ ratio. The samples were then eluted using petroleum ether and the aliphatic fractions were fractionated from each sample into a round-bottomed flask. Rotary evaporator (Cole-parmer, UK.) was used to remove the excess petroleum ether and the saturated hydrocarbons were transferred into GC vials and taken for GC analysis. The GC was carried out on a HewlettPackard 5890 gas chromatograph with a splitless injector, fitted with a flexible silica capillary coloum with internal diameter $30 \times 0.25 \mathrm{~mm}$. The oven temperature was programmed from 40 to $300^{\circ} \mathrm{C}$ at a rate of $4^{\circ} \mathrm{C} / \mathrm{min}$ and held at $300^{\circ} \mathrm{C}$ for $20 \mathrm{~min}$. About $1 \mu \mathrm{l}$ of each of the prepared samples were injected by an auto sampler. Helium was used as the carrier gas at a flow rate of $1 \mathrm{~m} / \mathrm{min}$. Samples were run using full scan, single ion monitoring (SIM).

\section{FT-IR}

The IR spectrum of each sample was recorded in triplicate using the FTIR (Nexus 870, Thermo Nicolet) (ATR equipment running 32 scans per spectrum). The spectra were collected and processed using the Omnic software. Various indices were calculated using ratios generated from peak areas rather than peak heights. This procedure is more reliable as it takes into consideration several vibrations of the same type occurring simultaneously (Permanyer et al., 2001). Table 1 shows some of the indices calculated and the formulae used.

Table 1: Indices and formulae used in deriving indices.

\begin{tabular}{l|l}
\hline Derived Indices & Formulae used \\
\hline Aromatic index & $\mathrm{A}_{1600} / \mathrm{A}_{T} \times 1000$ \\
Aliphatic index & $\mathrm{A}_{1450}+\mathrm{A}_{1370} / \mathrm{A}_{T} \times 100$ \\
Carbonyl index & $\mathrm{A}_{1700} / \mathrm{A}_{\top} \times 1000$ \\
Sulphoxide index & $\mathrm{A}_{1030} / \mathrm{A}_{T} \times 1000$ \\
Aliphatic (Long chain) index & $\mathrm{A}_{720} / \mathrm{A}_{\top} \times 1000$ \\
\hline
\end{tabular}

$\mathrm{A}=$ the area under the subscripted peak.

$A_{T}=$ the total sum of areas of absorption peaks for designated functional groups in the sample spectrum and is given by:

$A_{T}=A_{2950}+2920+2860+A_{1700}+A_{1600}+A_{1450}+A_{1370}+A_{1030}+$ $A_{870}+810+740$.

The subscripts (i.e. 1700,1600 , etc) represent the wave numbers at which the peaks occur.

\section{Partial least square analysis (PLS)}

Numerical calibration models were constructed using partial least squares regression (PLSR) on the generated indices for the oil mixtures as well as unmixed oil samples using the Statistics Unscrambler Software version 04. In PLSR computation, the complex relationship between a very large number of $X$ variables (Indices generated from Table 1) and one single $Y$ variable (mixed oil or sample) is compressed into a small number of linear combinations of the original $X$ variables. This was then used to make predictions for aliphatic contents of omitted samples (samples 10\% 
151 and $80 \%$ 151) to see how good they can be predicted. The PLSR equation was then used to predict aliphatic contents for five other samples namely 145 , 149, 172, H1 and AL10.

\section{RESULTS AND DISCUSSION Gas Chromatography}

Gas chromatograms were obtained for 100\% 151, $100 \% 145$ and the various other mixtures $(90,80,50$, 20 and 10\% 151). Figures $1(a-f)$ show the chromatograms obtained. The Gas chromatograms for oil sample 151 (Figure 1a) shows that most of the aliphatic components are either diminished or are missing completely and with a large hump of unresolved complex mixtures (UCM). This is evidence of severe biodegradation (Blanc and Connan, 1993). Oil sample 145 (Figure 1g) on the other hand still has most of its saturates including long chain $(C \geq 17)$ hydrocarbons. Figure $1(\mathrm{~b}-\mathrm{f})$ show gas chromatograms of different mixture of samples 151 and 145 (i.e. 90, 80, 50, 20 and $10 \%$ respectively). An increase in saturate peaks was observed with a corresponding decrease in the size of the UCM hump. This shows high sensitivity in the ability of GC in crude oil characterisation. The level of degradation of the oil can easily be detected.
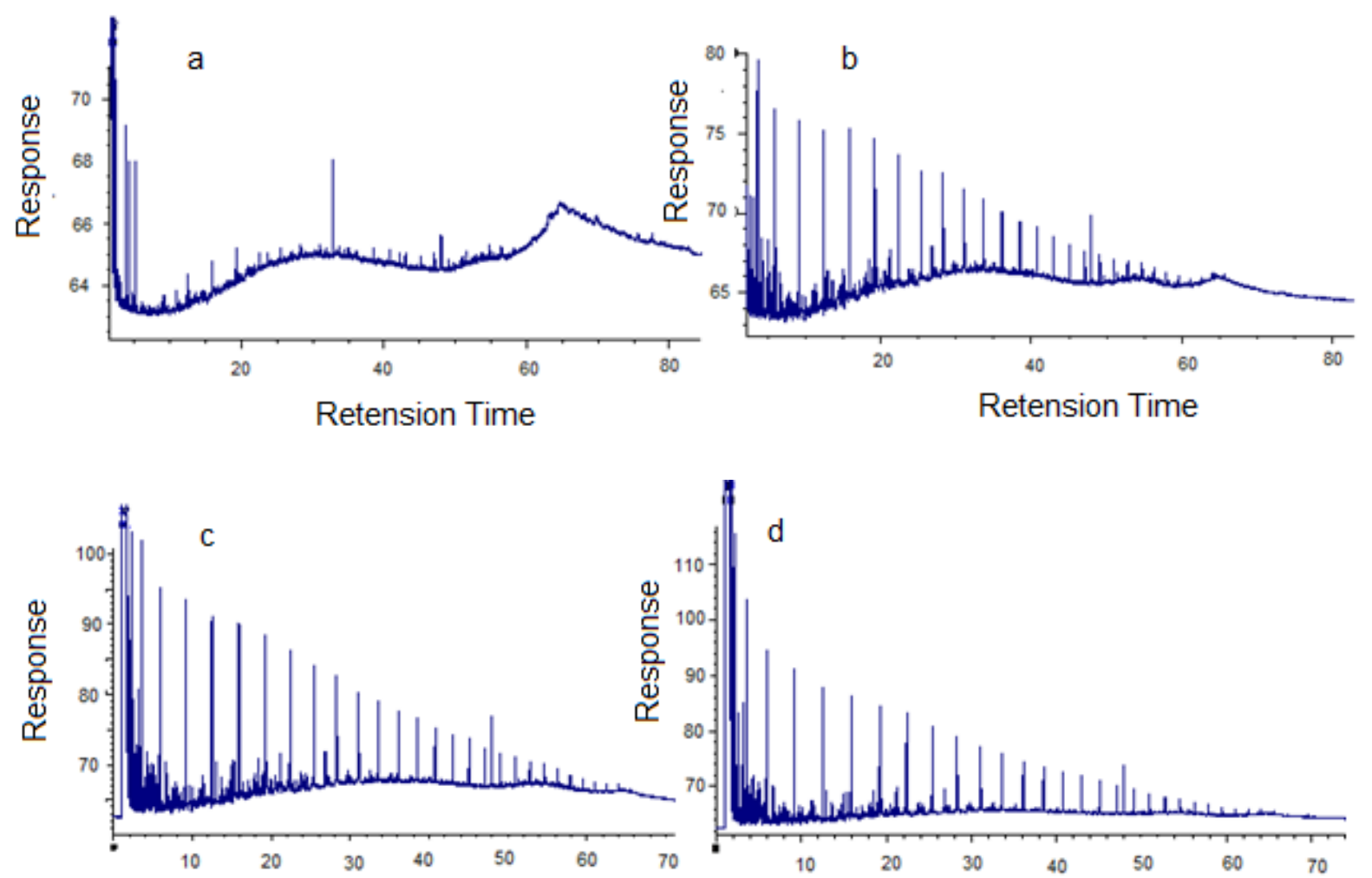

Retension Time
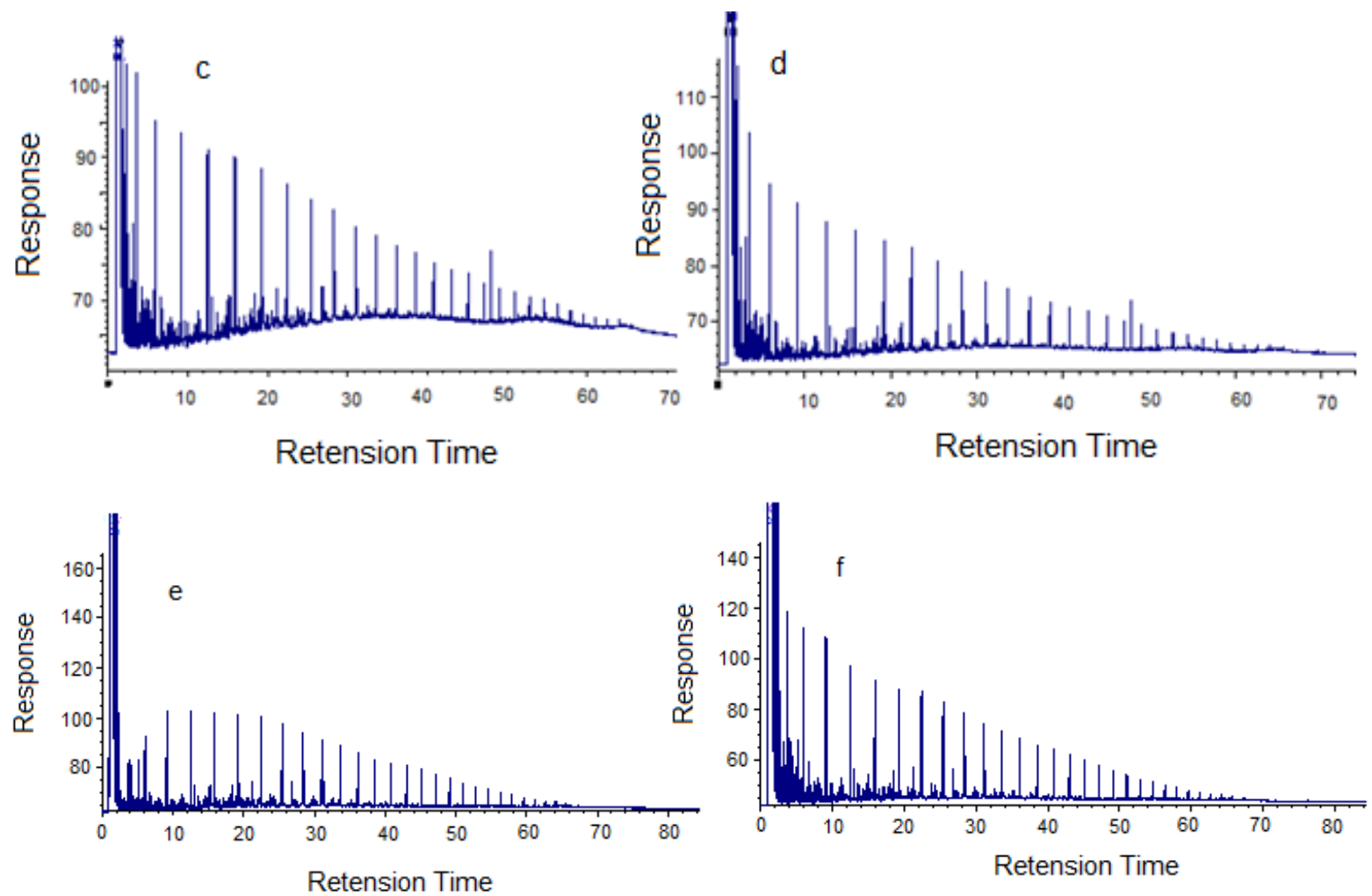


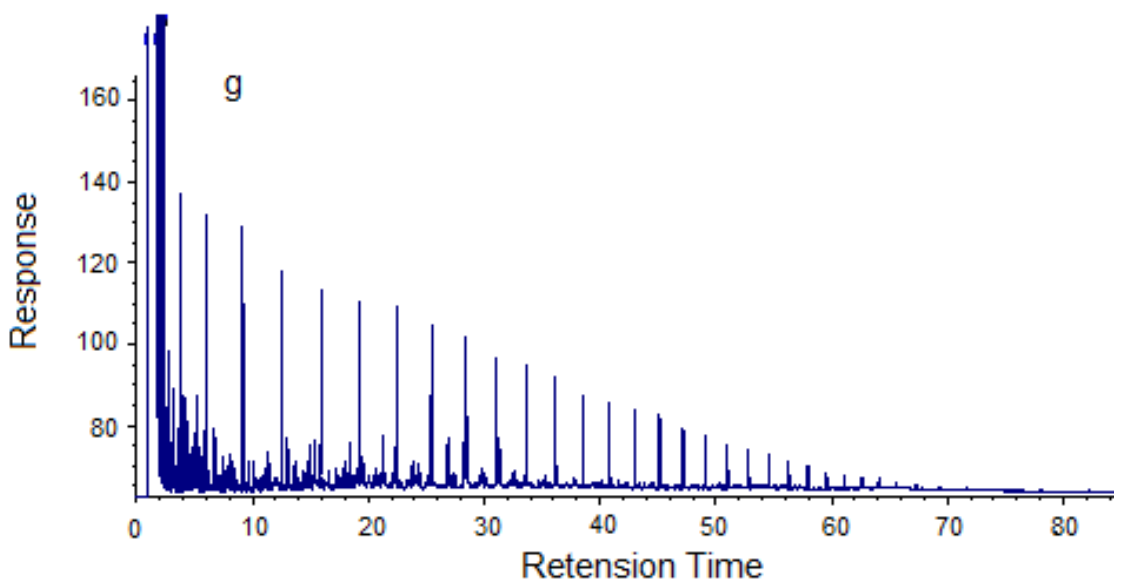

Figure 1: Showing Gas chromatograms for samples (a) $100 \%$, (b) $90 \%$, (c) $80 \%$, (d) $50 \%$, (e) $20 \%$ and (g) $10 \%$ of sample 151 and also $100 \%$ of sample 145 respectively.

agreement with the GC data. The intensity of the carbonyl/aromatic peaks gradually reduced as the

\section{FTIR}

The result obtained using the FT-IR technique agrees with the results of the gas chromatography technique. Although the relationship between the crude oils and the generated spectra is not a completely simple one; there are some complications. Especially with regards to the peaks in the $3000-2800 \mathrm{~cm}^{-1}$ region where absorption peaks for different groups tend to overlap (Aske et al., 2001; Hannisdal et al., 2005). Figure 2(a-c) shows the Infrared spectra obtained for some of the samples with the wavenumbers in $\mathrm{cm}^{-1}$ plotted against absorbance. The spectra show large carbonyl and aromatic peaks for sample 151 indicating heavy degradation in the oil sample in percentage of sample 151 is reduced from $90 \%$ to $0 \%(100 \% 145)$ indicating an increase in percentage of saturated hydrocarbons. The relationship between IR peaks and oil composition is somehow blurred by overlapping absorption peaks, yet, a quick visual inspection of the spectra would reveal some differences/trends in the $1750-650 \mathrm{~cm}^{-1}$ region. These are observed in the peak areas of the $C=0$ absorption at about $1700 \mathrm{~cm}^{-1}$, the $\mathrm{C}=\mathrm{C}$ absorption at about $1600 \mathrm{~cm}^{-1}$, the aromatic ring peaks between $890-730 \mathrm{~cm}^{-1}$ and the long chain aliphatic hydrocarbon vibration at about $720 \mathrm{~cm}^{-1}$, all of which tend to either increase or decrease depending on the composition/type of the crude oil involved.

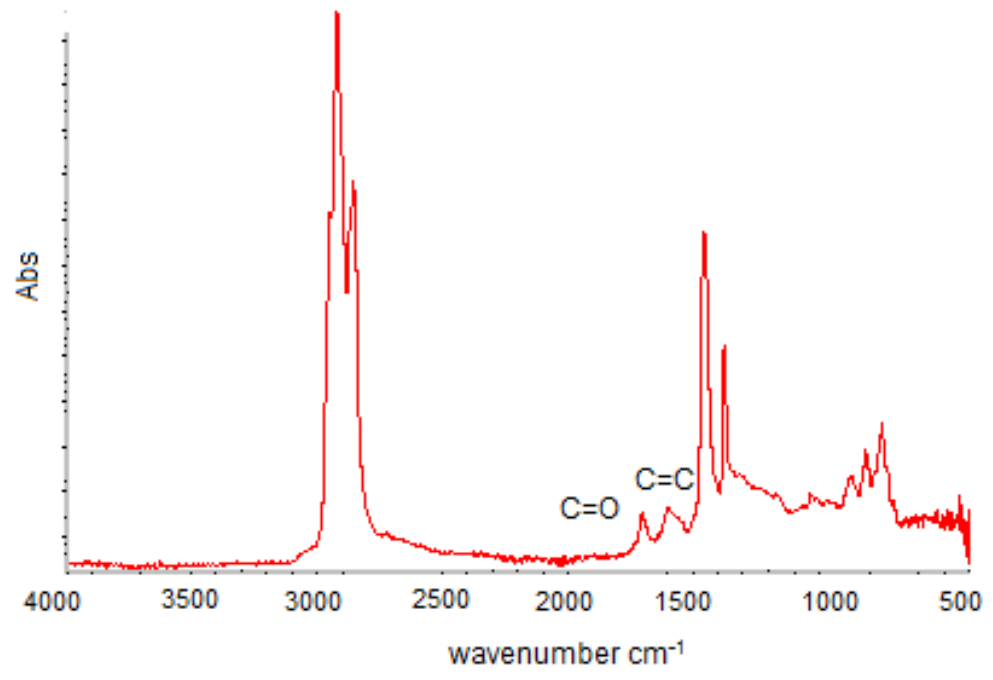

Figure 2(a): FTIR peaks for sample $151(100 \%)$ displaying large $C=0$ and $C=C$ peaks at around $1600 \mathrm{~cm}^{-1}$ 


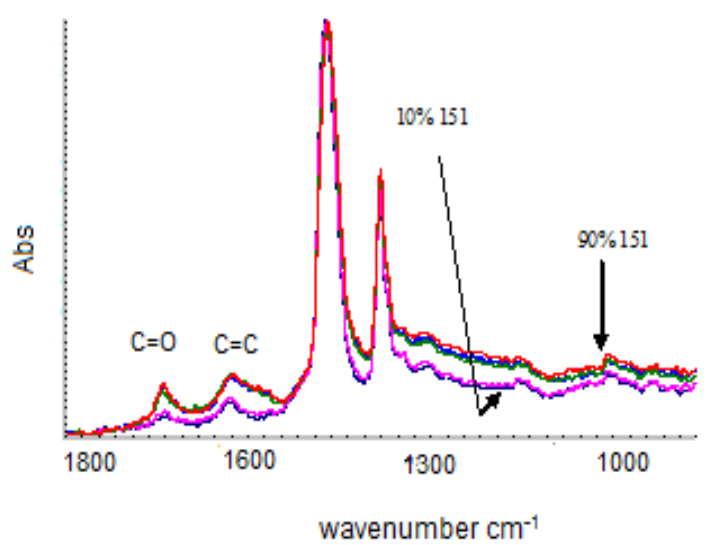

Figure 2(b): FTIR Spectra for samples 151 and 145 mixtures 90\%-10\%, 1800$900 \mathrm{~cm}^{-1}$, showing increase in peak area with increase in percentage of sample 151.

Figure 3(a) show spectra for samples 145 and 151 superimposed on each other at the same scale. The difference between the two spectra can be easily seen in the large area of the $\mathrm{C}=0$ peak at about $1699 \mathrm{~cm}^{-1}$ which is due to severe photooxidation/degradation in sample 151. This is in agreement with sample gas chromatography result in Figures 1(a) and (f) which show that sample 151 is highly degradedand also the large $\mathrm{C}=\mathrm{C}$ peak at about $1600 \mathrm{~cm}^{-1}$ for sample 151 which is due to the high percentage of aromatic molecules. This absorption, together with the aromatic ring bands between 890 and $730 \mathrm{~cm}^{-1}$ also give information on the abundance of resins and asphaltenes in the samples.

This is also true for sample 160 and 151 (Figure $3(\mathrm{~b})$ ), where except for the $\mathrm{C}=\mathrm{C}$ absorption which is quite large in both spectra (in agreement with latroscan results not shown here), the $\mathrm{C}=0$ peak for sample 160 is quite small, indicating that sample 160 may not have been photo-oxidized/degraded to

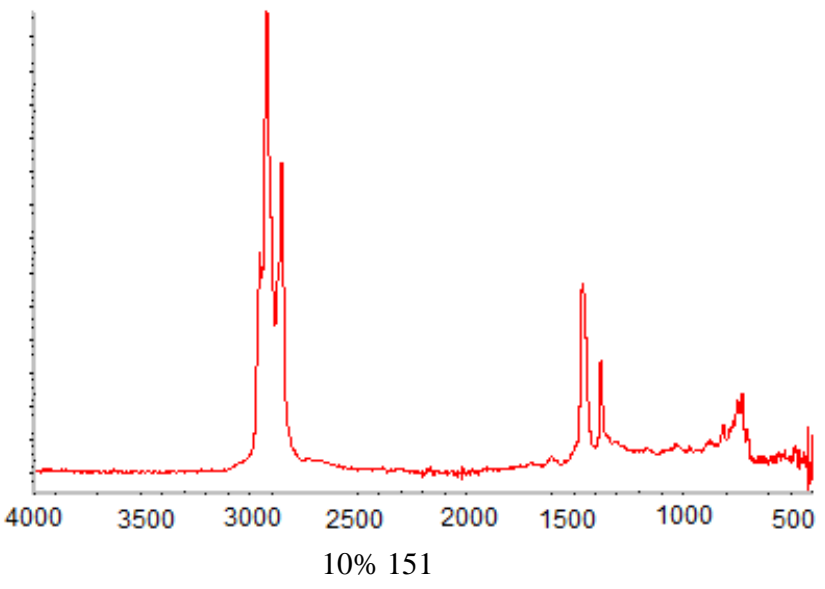

Figure. 2(c): FTIR Spectra for sample 100\% 145, the carbonyl and $\mathrm{C}=\mathrm{C}$ peaks are missing at about $1600 \mathrm{~cm}^{-1}$ are missing

the same degree as sample 151. Also the bands between 870 and $730 \mathrm{~cm}^{-1}$ are relatively smaller for sample 160, indicating that the sample resin/asphaltene content is lower.

Figure 3(c) shows the result of the spectral subtraction of samples 151 and 145. The troughs show the difference in area between the spectra involved. The carbonyl and aromatic absorptions are very conspicuous for the samples 151 and 145 subtraction, these results agree with the GC chromatograms which shows that sample 151 was highly degraded while 145 was not.

The relationship between peak areas and composition can be more easily seen when the spectra for the mixture of samples 151 and 145 are considered (Figure $2 b$ ). The decrease in peak areas for $\mathrm{C}=\mathrm{O}$ and aromatic absorptions can be easily seen with decrease in the percentage of sample 151 present while the aliphatic peaks tend to increase or remain fairly constant. Hence, crude oil composition and its degree of biodegradation can be roughly inferred from simple visual analysis of the sample spectra. 


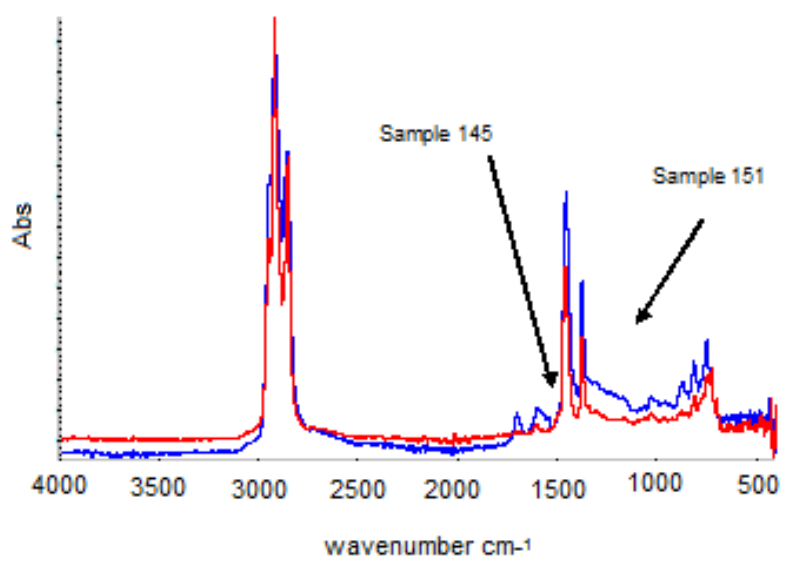

Figure. 3(a): Spectra for samples 145 and 151 plotted in the same window

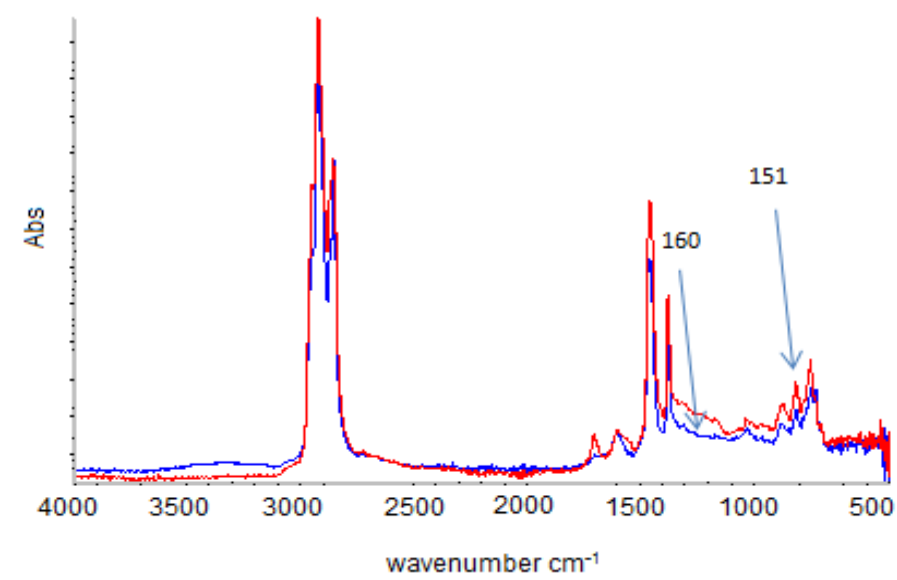

Figure 3b: Spectra for samples 160 \& 151 superimposed.

More aliphatic peaks occur in 160 than there are in 151.

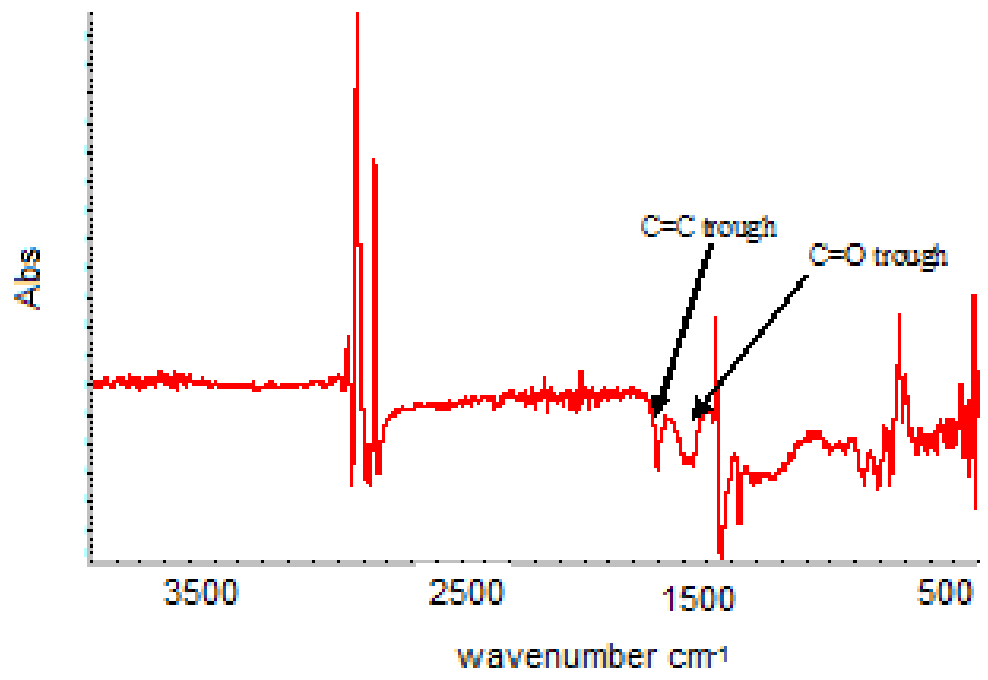

Figure 3(c): Spectral Subtraction of Peaks for Samples 151 and 145

\section{Partial least square Regression (PLSR)}

Partial least squares regression which was carried out on the samples of oil mixtures show an interesting result. Two oil samples spectra (samples 10\% 151 and $80 \% 151$ ) were omitted and the PLSR calibration equation was used to predict this two samples. Based on the calibration equation, the mixture containing $10 \% 151$ was predicted as containing $11.55 \% 151$, with a standard deviation of 0.09 and the oil containing $80 \% 151$ was predicted as containing 
$77.01 \%$ with a deviation of 0.08 (Figure 4a). This is a very good result as the error is minimal. Similarly PLSR prediction carried out on five other samples produced an interesting result. Saturates for five samples (namely 145, 149, 172, H1 and AL10 (Table 2)) where predicted using the PLSR calibration equation against data obtained from the peak indices of the aliphatic fractions (see Table 1). Figure $4 \mathrm{~b}$ shows the predicted values for the samples and the standard deviations. The predictions are very good, with standard deviations as shown in the plot and also in Table 3. The coefficient of correlation for this data is very high $\left(R^{2}=0.9613\right)$. This goes to further support the strength of FTIR in characterising crude oil especially when combined with chemometrics (i.e. PLSR, PCA, etc.). Previous work (Hannisdal et al., 2005) shows that IR spectra are able to predict both the aliphatic and resin contents of crude oil very well. Similar prediction could not be achieved here for resins because, unlike in the previous work where samples were initially separated into SARA fractions which made it easy to make predictions on each SARA fraction, here IR spectra were obtained for the bulk crude oils. This means that although the aliphatic peaks could be easily pointed out and used for the aliphatic prediction, it would be very difficult if not impossible to distinguish peaks for resins and asphaltenes because the peaks occur together.

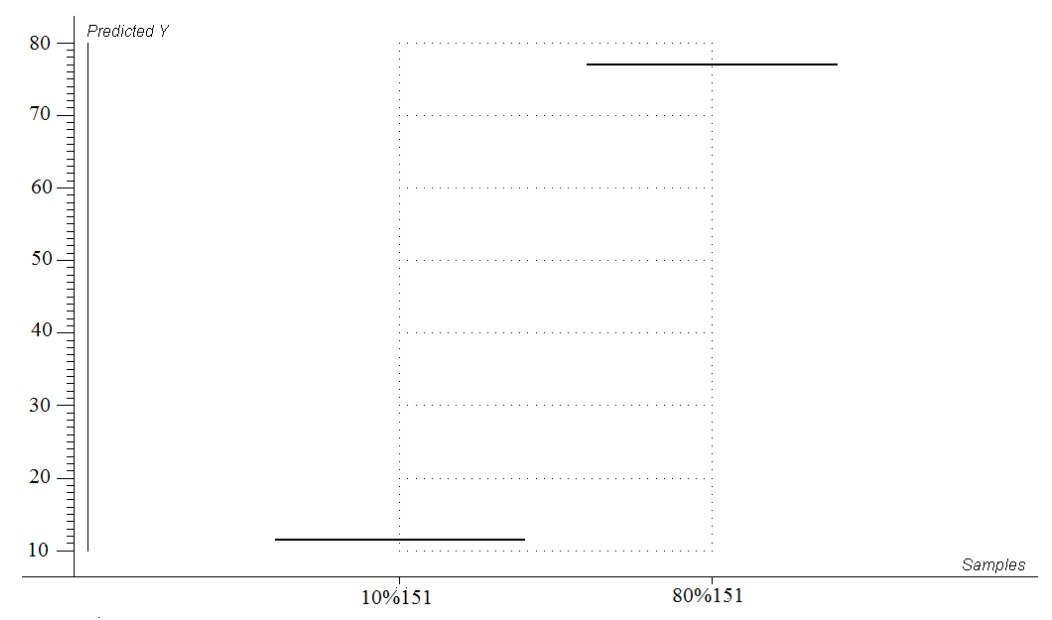

Figure 4a: Predicted values for $10 \%$ and $80 \%$ mixtures.

Thick lines indicate standard errors of 0.09 and 0.08 respectively for both predictions. The prediction is very good.

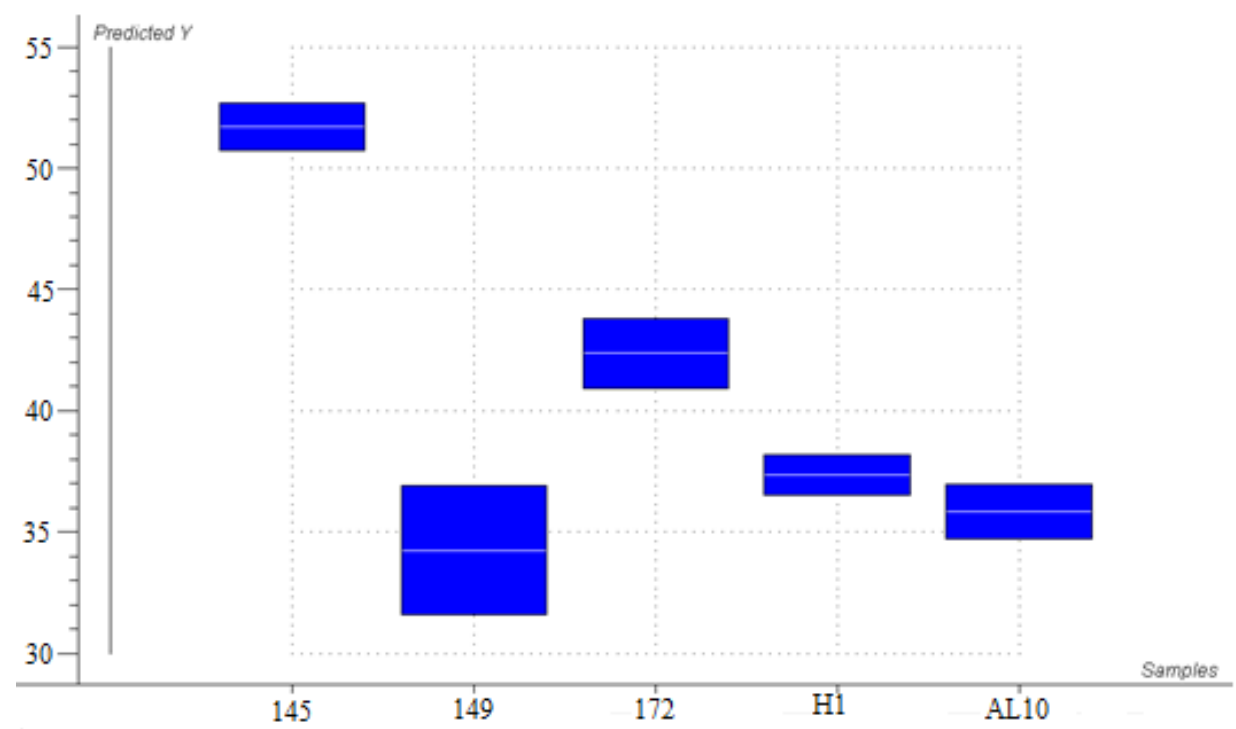

Figure 4b: Predicted plots for saturated hydrocarbon of five samples (145, 149, 172, H1 and AL10). Prediction is also very good 
Table 2: Measured and Predicted Values Together with the Deviations.

\begin{tabular}{c|c|c|c}
\hline Sample & Measured Saturates & Predicted Saturates & Deviation \\
\hline 145 & 53.36 & 51.70 & 0.97 \\
149 & 31.6 & 34.24 & 2.66 \\
172 & 40.18 & 42.36 & 1.45 \\
H1 & 33.73 & 37.34 & 0.84 \\
AL10 & 36.19 & 35.85 & 1.11 \\
\hline
\end{tabular}

\section{CONCLUSION}

The results obtained from this work show that IR spectroscopy is indeed a viable tool for characterising crude oils which could substitute present traditional fractionation procedures. The strength of FTIR can be increased by combination with Partial Least Square analysis. Partial least square calibration equation applied on indices generated from FTIR data was used to predict aliphatic contents for two samples from the oil mixtures $(10 \%$ and $80 \% 151)$ and the saturates for five other sample $(145,149,172, \mathrm{H} 1$ and $A L 10)$ within a statistically agreeable range.

\section{REFERENCES}

Akrami, H.A., Yardim, M.F., Akar, A. and Ekinci, E. (1997). FT-IR characterization of pitches derived from Avgamasya asphaltite and Raman-Dincer heavy crude, Fuel, 76: 1389-1394.

Aske, N. (2002). Characterisation of crude oil components, asphaltene aggregation and emulsion stability by means of near infrared spectroscopy and multivariate analysis. Thesis submitted to the Department of Chemical Engineering. Norwegian University of Science and Technology. Tsondheim. 58pp.

Aske, N., Kallevic, H. and Sjoblom, J. (2001). Determination of Saturate, Aromatic, Resin and Asphaltenic (SARA) components in Crude oils by means of Infrared, Near-Infrared spectroscopy. Energy and Fuels, 15: 1304-1312.

Boukir, A., Aries, E., Guiliano, M., Asia, L., Doumenq, P. and Mille, G. (2001). Subfractionation, characterization and photooxidation of crude oil resins. Chemosphere, 43: 279-286.

Chung, H. and Ku, M.-S. (2000). Comparison of Near-Infrared, Infraredand Raman spectroscopy for the analysis of Heavy petroleum products. Applied spectroscopy, 54: 239-245.

Connan, J. (1984). Biodegradation of Crude Oils in reservoirs. Advances in Petroleum Geochemistry, 1: 299-335.

Blanc, P.H. and Connan, J. (1993). Crude oils in reservoirs: the factors influencing their composition. IN: M. L. Boldenave (ed), Applied Petroleum Geochemistry, Pp 149-174.

El-hadi, D. and Bezzina, M. (2005). Improved empirical correlation for petroleum fraction composition quantitative prediction. Fuel, 84: 611-617.

Griffiths, P.R. (1978). Fourier Transform Infrared Spectroscopy: Theory and Instrumentation. In GRIFFITHS P.R. (ed) Fourier Transform Infrared Spectroscopy, Transforms Techniques in Chemistry, pp. 109-173. New York and London: Plenum Press.

Hannisdal, A., Hemmingsen, P.V. and Sjoblom, J. (2005). Group-Type analysis of heavy crude oil using vibrational spectroscopy in combination with Multivariate analysis. Industrial and Engineering Chemistry Research, 44(5): 13491357.

Hosamani, K.M. and Ganjihal, S.S. (2003). Unique occurrence of unusual fatty acids in Ochrocarpus africanus seed oil. Industrial Crops and Products 18: $111-116$.

Hunt, J.M. (1995). Petroleum Geochemistry and Geology, (2nd edition). W. H. Freeman and company, New York, U.S.A. Pp 743

Hunt, J.M., Philp, R.P. and Kvenvolden, K.A. (2002). Early developments in petroleum geochemistry. Organic Geochemistry, 33: 1025-1052.

Jacquot, F., Guiliano, M., Doumenq, P., Munoz, D. and Mille, G. (1996). In vitro photoxidation of crude oil maltenic fractions: Evolution of fossil biomarkers and polycyclic aromatic hydrocarbons. Chemosphere, 33: 671-681.

Kemp, W. (1991). Organic Spectroscopy. (3'd edition), Macmillan, Hampshire, England. Pp 393.

Larter, S.R. and Aplin, A.C. (1995). Reservoir geochemistry: methods, applications and opportunities. In: Cubitt, J. M. and England, W. A. (eds) The geochemistry of reservoirs, Geological Society Special Publication, 86: Pp 532.

Olalere, G.A. (2003). Use of fluorescence spectroscopy for characterising physical properties of degraded and nondegraded crude 
oil. Dissertation submitted to the school of Civil Engineering and Geosciences, Newcastle University.

Permanyer, A., Douifi, L., Lahcini, A., Lamontagne, J. and Kister, J. (2002). FTIR and SUVF spectroscopy applied to reservoir compartmentalization: a comparative study with gas chromatography fingerprints results. Fuel, 81: 861-866.

Peters, K. E. and Fowler, M.G. (2002). Applications of petroleum geochemistry to exploration and reservoir management. Organic Geochemistry, 33: 5-36.

Roehner, R. M.and Hanson, F.V. (2001). Determination of wax precipitation temperature and amount of precipitated solid wax versus temperature for crude oils using FT-IR spectroscopy. Energy and Fuels, 15: 756-763.

Ryder, A.G., Glynn, T.J., Feely, M. and Barwise, A.J.G. (2002). Characterization of crude oils using fluorescence lifetime data. Spectrochimica Acta Part A: Molecular and Biomolecular Spectroscopy, 58: 1025-1037.

Sjoblom, J., Aske, N., Harald Auflem, I., Brandal, O., Erik Havre, T., Saether, O., Westvik, A., Eng Johnsen, E. and Kallevik, H. (2003). Our current understanding of water-in-crude oil emulsions. Recent characterization techniques and high pressure performance. Advances in Colloid and Interface Science, 100-102: 399-473. 